\title{
A Novel 3d Printed Curved Monopole Microstrip Antenna Design for Biomedical Applications
}

\section{Mustafa Berkan Biçer}

Bakırçay Üniversitesi: Bakircay Universitesi

\section{Emine Avşar Aydın ( $\nabla$ eaydin@atu.edu.tr)}

Adana Alparslan Turkes Bilim ve Teknoloji Universitesi https://orcid.org/0000-0002-5068-2957

\section{Research Article}

Keywords: bandwidth enhancement, biomedical, curved substrate, monopole antenna, printed antenna.

Posted Date: June 2nd, 2021

DOl: https://doi.org/10.21203/rs.3.rs-532332/v1

License: (9) This work is licensed under a Creative Commons Attribution 4.0 International License. Read Full License 


\title{
A NOVEL 3D PRINTED CURVED MONOPOLE MICROSTRIP ANTENNA DESIGN FOR BIOMEDICAL APPLICATIONS
}

\author{
Mustafa Berkan Bicer \\ Izmir Bakircay University, Department of Electrical and Electronics Engineering, Menemen, \\ Izmir, Turkey. mustafa.bicer@bakircay.edu.tr \\ Emine Avsar Aydin \\ Adana Alparslan Turkes Science and Technology University, Department of Aerospace \\ Engineering, Saricam, Adana, Turkey. \\ Corresponding Author: rasvaenime@gmail.com or eaydin@atu.edu.tr
}

\begin{abstract}
This paper proposes a novel and compact monopole microstrip antenna (MA) design with a three-dimensional (3D) printed curved substrate for biomedical applications. A curved substrate was formed by inserting a semi-cylinder structure in the middle of the planar substrate consisting of polylactic acid (PLA). The antenna was fed with a microstrip line, and a partial ground plane was formed at the bottom side of the substrate. The copper plane with two triangular slots is arranged on the curved semi-cylinder structure of the substrate. The physical dimensions of the radiating plane and ground plane were optimally determined with the use of the sparrow search algorithm (SpaSA) to provide a wide $-10 \mathrm{~dB}$ bandwidth between $3 \mathrm{GHz}$ and $12 \mathrm{GHz}$. A total of six microstrip antennas having different parameters related to physical dimensions were designed and simulated to compare the performance of the proposed antenna with the help of full-wave electromagnetic simulation software called CST Microwave Studio. The proposed curved antenna was fabricated, and a PNA network analyzer was used to measure the $S_{11}$ of the proposed antenna. It was demonstrated that the measured $S_{11}$ covers the desired frequency range.
\end{abstract}

Keywords: bandwidth enhancement, biomedical, curved substrate, monopole antenna, printed antenna.

\section{Introduction}

Due to their remarkable characteristics, including small size, flat structure, low-cost, conformal modeling, ease of production, and simple integration with solid-state devices, microstrip antennas (MAs) have been extensively utilized in a variety of applications such as aircraft, space, and satellite communication systems, missile applications, biomedical devices, sensors and devices that demand small-sized antennas [1]. Although MAs have a number of attractive features, their primary drawbacks include their low efficiency, inability to handle large amounts of power, insufficient polarity purity, poor scanning capacity, large size for lower frequencies, and narrow bandwidths [1]. Most studies on MAs have focused on conventional radiating plane geometries such as circular, triangular, or rectangular that are simple to manufacture on planar surfaces. Since the physical dimensions of MAs and their operating frequencies are inversely proportional, conventional geometries need to be modified by extending the resonance length in order to design an antenna operating at low frequencies. Besides the radiating patch geometry, the physical and electrical properties of the substrate play an essential role in determining the characteristics of MAs such as bandwidth, impedance, and radiation pattern. Although narrow bandwidths are needed for government-owned security systems and some applications operating at a specific band, wider bandwidths are required for applications such as biomedical imaging systems or ultra-wideband systems (UWB). Various approaches, such 
as increasing the thickness or dielectric constant of the substrate, are used to enhance the bandwidth and efficiency of an MA. However, as the thickness of the layer increases, undesired surface waves arise, reducing the total amount of power available for direct radiation. Surface waves propagate through the substrate and radiate from curved and discontinuous surfaces, such as dielectric and ground plane shear, affecting the characteristics of the antenna, including radiation pattern and polarization. By using gaps, it is possible to minimize surface waves while ensuring a wide bandwidth. A further strategy for enhancing bandwidth is to utilize substrates with higher dielectric constants. Although theoretically high dielectric constants may be used in antenna design to improve the bandwidth, the dielectric constants of the materials used in the manufacturing of an MA are typically between 2.2 and 12 [1]. Substrate materials with a low thickness value are widely preferred as they provide improved performance, enhanced bandwidth, and less restricting structures for radiation areas. Various techniques are utilized to manufacture MAs, including wet-etching, inkjet printing, screen printing, and threedimensional (3D) printing [2-20]. 3D printing has a promising potential in antenna manufacturing as it allows faster, more convenient, and less expensive manufacturing than the conventional tech techniques, known as additive manufacturing [10,11]. Thus, by using techniques not achievable in traditional manufacturing, 3D printing enables the production of more lightweight antennas for desired applications. Zhu et al. [2] aimed to enhance the bandwidth of an antenna under dual resonance by simultaneously exciting the $\mathrm{TM}_{101}$ and $\mathrm{TM}_{211}$ modes. Although manufacturing the antenna [2] using conventional methods is complicated and expensive, it can be easily produced for the desired purposes using 3D printing technology. $\mathrm{Gu}$ et al. [3] proposed a resonance gap-based design and production of an all-metal D-band antenna in the millimeter waveband. The study [3] utilizes a novel impedance matching technique to improve the $S_{11}$ bandwidth. In [14], Lomakin et al. presented the use of a hookshaped feeding structure for helical antenna design via stereolithography (SLA) printed integration. The advantage of SLA printing in antenna manufacturing is that it achieves a higher degree of detail, layered printing, and surface quality. The center frequency of the proposed antenna was obtained to be $77 \mathrm{GHz}$ with a bandwidth of about 20 percent as a result of a simulation [14]. Sarjoghian et al. [15] proposed a 3D-printed pyramidal double-ridged horn antenna filled with high-dielectric material. The manufactured antenna is utilized for measuring and verifying the thickness of abdominal fat [15]. In [16], Raniszewski et al. introduced a dielectric-filled antenna with the aim of reducing the size. Four air-filled and twenty-four dielectric-filled antennas were designed to evaluate the impact of the 3D printed model [16]. The study [16] demonstrates good agreement between the simulated and measured results for both antennas, as well as the significant impact of 3D printing technology on the S-parameter. In [17], Njogu et al. developed a wearable nail antenna with the aid of 3D printing technology and verified that the measured impedances at $15 \mathrm{GHz}$ and $28 \mathrm{GHz}$ are found to be well-matched. Mitra et al. [18] proposed a new antenna made with an improved version of the Electrified conductive filament on a planar TMM4 substrate for use in emerging space applications such as 3D printed satellites, spacesuits, and zero-gravity experiments. The antenna was designed to operate in the S-band at the frequency of $2.56 \mathrm{GHz}$ and the 3D-printed antenna was measured. Aysu Belen et al. [19] introduced a novel antenna model consisting of six lens plates with rectangular feeds varying in diameter and thickness. Nowadays, MAs for biomedical applications can be modeled and manufactured in a variety of ways utilizing 3D printing technology. Both the radiating planes of the antenna and the substrate can be manufactured using 3D printing technology. Muntoni et al. [13] proposed a novel 3D printed substrate structure to enhance the bandwidth and reduce the size of a microstrip antenna. In [13], rather than increasing the thickness of the entire substrate to prevent the surface waves or spurious radiation, the thickness of the area containing the radiating patch is increased using semi- 
cylinder geometry. By introducing a curved structure onto the substrate proposed in [13], the bandwidth of a coaxially fed MA was increased from 2.9 percent to 9 percent.

In this study, an MA configuration with two triangular slots on the curved substrate fed by a microstrip line is proposed for biomedical applications. For this purpose, a curved structure with semi-cylindrical geometry was formed in the middle of a thin polylactic acid (PLA) substrate as presented by Muntoni et al. [13]. Subsequently, a rectangular radiating copper plane was used to cover the curved surface, and two triangular slots were formed on the copper plane to provide a wider bandwidth between $3 \mathrm{GHz}$ and $12 \mathrm{GHz}$. The proposed antenna was fed by a microstrip line, and a partial ground plane was used at the bottom side of the substrate. The antenna was designed and simulated using CST Microwave Studio, and the optimal dimensions were estimated by utilizing the sparrow search optimization algorithm. The substrate of the antenna is manufactured using PLA material with the aid of 3D printing technology, and the copper planes are formed by adhering copper tape. The characteristics of the state-of-art studies chosen from the literature are summarized in Table 1.

Table 1. The characteristics of the state-of-art studies on antenna design for biomedical applications.

\begin{tabular}{|c|c|c|c|c|c|c|}
\hline$\#$ & Substrate Type & $\begin{array}{c}\text { Size } \\
(\mathrm{mm})\end{array}$ & $\begin{array}{c}\text { Frequency } \\
(\mathbf{G H z})\end{array}$ & Conductive Material & Substrate Material & $\begin{array}{l}\text { Gain } \\
\text { (dBi) }\end{array}$ \\
\hline$[22]$ & $\begin{array}{c}\text { Not 3D Printed } \\
\text { Planar }\end{array}$ & $80 \times 67 \times 3.4$ & $3.7-10.3$ & $\begin{array}{l}\text { Nickel-copper-silver- } \\
\text { coated nylon }\end{array}$ & PDMS & $\sim 8$ \\
\hline$[23]$ & $\begin{array}{c}\text { Not 3D Printed } \\
\text { Planar }\end{array}$ & $31 \times 31$ & $3.8-18.1$ & Copper & FR-4 & 6.5 \\
\hline [21] & $\begin{array}{c}\text { Not 3D Printed } \\
\text { Planar }\end{array}$ & $3.5 \times 10 \times 1$ & $3-12$ & Copper & Jeans & 5.47 \\
\hline [24] & $\begin{array}{l}\text { Not 3D Printed } \\
\text { Circle-shaped } \\
\text { radiator and } \\
\text { microstrip fed } \\
\text { line }\end{array}$ & radius $=12$ & $2.8-16$ & Copper & Cotton & $\sim 4$ \\
\hline$[25]$ & $\begin{array}{c}\text { Not 3D Printed } \\
\text { Planar }\end{array}$ & $32 \times 52 \times 0.28$ & $4-8$ & $\begin{array}{c}\text { Graphene-assembled } \\
\text { film }\end{array}$ & Ceramic & 4.1 \\
\hline [2] & $\begin{array}{l}\text { 3D Printed } \\
\text { Spherical }\end{array}$ & radius $=12$ & $9.77-14.8$ & $\begin{array}{l}\text { Electroless copper } \\
\text { plating }\end{array}$ & SLA & 11.2 \\
\hline$[3]$ & $\begin{array}{l}\text { 3D Printed } \\
\text { Planar }\end{array}$ & $\begin{array}{c}\max . \text { size of } \\
\text { about } 3 \lambda\end{array}$ & $130-150$ & $\begin{array}{l}\text { All metal and copper } \\
\text { metallization }\end{array}$ & $\begin{array}{c}\text { All metal and copper } \\
\text { metallization }\end{array}$ & $\begin{array}{l}15.5 \\
12.1\end{array}$ \\
\hline [13] & $\begin{array}{l}\text { 3D Printed } \\
\text { Curved }\end{array}$ & $71.5 \times 71.5 \times 2$ & $2-3$ & Copper & PLA & 6.3 \\
\hline [17] & $\begin{array}{l}\text { 3D Printed } \\
\text { Curved }\end{array}$ & $14.96 \times 17.45$ & 15 and 28 & Nanoparticle silver ink & ABS fingernail & 7.5 \\
\hline$[18]$ & $\begin{array}{l}\text { 3-D Printed } \\
\text { Planar }\end{array}$ & $51 \times 51 \times 1.52$ & $1-4$ & Electrifi & TMM4 & 4.23 \\
\hline $\begin{array}{l}\text { Our } \\
\text { Study }\end{array}$ & $\begin{array}{l}\text { 3D Printed } \\
\text { Curved }\end{array}$ & $71.5 \times 71.5 \times 2$ & $3-11$ & Copper & PLA & $3 \sim 5$ \\
\hline
\end{tabular}

\section{Methodology}

\subsection{Sparrow Search Algorithm Overview}

Optimization algorithms, which are widely used in engineering applications such as data classification, route planning, robotic control, are also used to solve electromagnetic problems such as designing antennas and obtaining dielectric maps in tomographic microwave imaging. Swarm-based meta-heuristic optimization algorithms are inspired by the foraging behavior of animals in obtaining the best food sources and can be applied to a wide variety of problems thanks to their features, such as simple application and flexibility. The sparrow search algorithm (SpaSA) used in this study is a swarm-based optimization algorithm proposed by Xue and Shen [26] that simulates the foraging behavior of sparrows. Sparrows are classified into two groups 
as producers and scroungers. Sparrows with generally high energy levels are considered as producers, and these sparrows take on the task of looking for rich food sources or choosing a direction for the foraging of scroungers. The energy level is determined by evaluating the fitness value of each individual in the swarm. When a predator is detected, individuals of the swarm begin to chirp. When their chirping levels exceed a certain safety threshold, producer sparrows take scroungers to a safe area. Each individual in the group can become a producer as long as they seek good food sources so that the distribution within the population does not change. Scroungers, on the other hand, follow producers who are looking for the best food source. While the sparrows on the outer edge of the swarm move towards the safe area in case of danger, the sparrows in the middle of the swarm randomly walk to be close to the other individuals [26]. In SpaSA, the sparrow positions are defined as given in Equation (1) [26],

$$
x=\left[\begin{array}{cccr}
x_{1,1} & x_{1,2} & \mathrm{~L} & x_{1, d} \\
x_{2,1} & x_{2,2} & \mathrm{~L} & x_{2, d} \\
\mathrm{M} & \mathrm{M} & \mathrm{M} & \mathrm{M} \\
x_{n, 1} & x_{n, 2} & \mathrm{~L} & x_{n, d}
\end{array}\right]
$$

where $n$ represents the number of sparrows and $d$ represents the number of problem variables to be optimized. Then, fitness values are calculated by considering the position of each individual. Individuals with the highest fitness score are more important than others in the foraging process. Producer sparrows search for food in larger areas than scroungers. The positions of producer sparrows in each iteration are determined using Equation (2) [26].

$$
x_{i, j}^{t+1}= \begin{cases}x_{i, j}^{t} e^{\frac{-i}{\alpha \cdot i t e_{\max }}} & r_{2}<s t \\ x_{i, j}^{t}+q \cdot l & r_{2} \geq s t\end{cases}
$$

The variables $t, i, j$, and iter $_{\text {max }}$ in Equation (2) represent the current iteration, the sparrow in the $t^{\text {th }}$ iteration, the dimension variable of the $i^{\text {th }}$ sparrow in the $t^{\text {th }}$ iteration, and the maximum number of iterations, respectively. In addition, the randomness parameters $a, q, l, r_{2}$, and $s t$ are, respectively, a uniformly distributed random number between $(0,1]$, a random number with normal distribution, $1 x d$-dimensional vector filled with ones, an alarm value which is a uniformly distributed random number between $[0,1]$ and a safety threshold value which is a uniformly distributed random number between $[0.5,1]$. An $r_{2}$ value lower than the st value indicates that there are no predators around the swarm. If there are no predators around, producer sparrows may seek food in large areas. However, if the sparrows detect a predator, that is, if the value of $r_{2}$ is greater than $s t$, the individuals go into alarm status. When an alarm status occurs, all sparrows must quickly go to the nearest safe area. Some scroungers in the group follow the producers. When these producers find a good food source, scroungers quickly go to that resource and fight to get the food. The positions of the scroungers are calculated using Equation (3) [26].

$$
\begin{aligned}
& x_{i, j}^{t+1}= \begin{cases}q \cdot e^{\left(\frac{x_{\text {wosst }}^{t}-x_{i, j}^{t}}{i^{2}}\right)} & i>\frac{n}{2} \\
x_{p}^{t+1}+\left|x_{i, j}^{t}-x_{p}^{t+1}\right| \cdot A^{+} \cdot l & \text { otherwise }\end{cases} \\
& A^{+}=A^{T}\left(A A^{T}\right)^{-1}
\end{aligned}
$$


In Equation (3), $x_{p}, x_{\text {worst }}$ and $A$ parameters denote the optimal position of the producer sparrow, global worst position, and the $1 x d$-dimensional vector consisting of random numbers selected in the range of $[-1,1]$. The condition $i>n / 2$ defines that the $i^{\text {th }}$ scrounger with the worst fitness score is about to starve. The positions for the sparrows who are on the edge of the swarm and go to the nearest safe position when they detect a danger are updated according to Equation (5) [26].

$$
x_{i, j}^{t+1}= \begin{cases}x_{\text {best }}^{t}+\beta \cdot\left|x_{i, j}^{t}-x_{\text {best }}^{t}\right| & f_{i}>f_{g} \\ x_{i, j}^{t}+k \cdot\left(\frac{\left|x_{i, j}^{t}-x_{\text {worst }}^{t}\right|}{\left(f_{i}-f_{w}\right)+\varepsilon}\right) & f_{i}=f_{g}\end{cases}
$$

In Equation (5), $x_{\text {best }}, f_{i}, f_{g}$, and $f_{w}$ parameters represent the global best position, fitness value of the $i^{\text {th }}$ sparrow, global best fitness, and global worst fitness values, respectively. While the direction of movement parameter $K$ is a random number in the range of [-1, 1], $\varepsilon$ is a very small number chosen to avoid a division by zero error, and in this study, it is taken as $10^{-10}$. The step size control parameter $\beta$ is a random number with a mean of 0 and a variance of 1 , chosen randomly according to the normal distribution, and $x_{\text {best }}$ represents the center position. It is assumed that the sparrows that meet the $f_{i}>f_{g}$ condition are located on the outer edge of the swarm, while the sparrows that provide the $f_{i}=f_{g}$ condition are assumed to be located in the center of the group [26]. The pseudocode for sparrow search algorithm (SpaSA) is given in Algorithm 1.

Algorithm 1 Pseudocode for Sparrow Search Algorithm

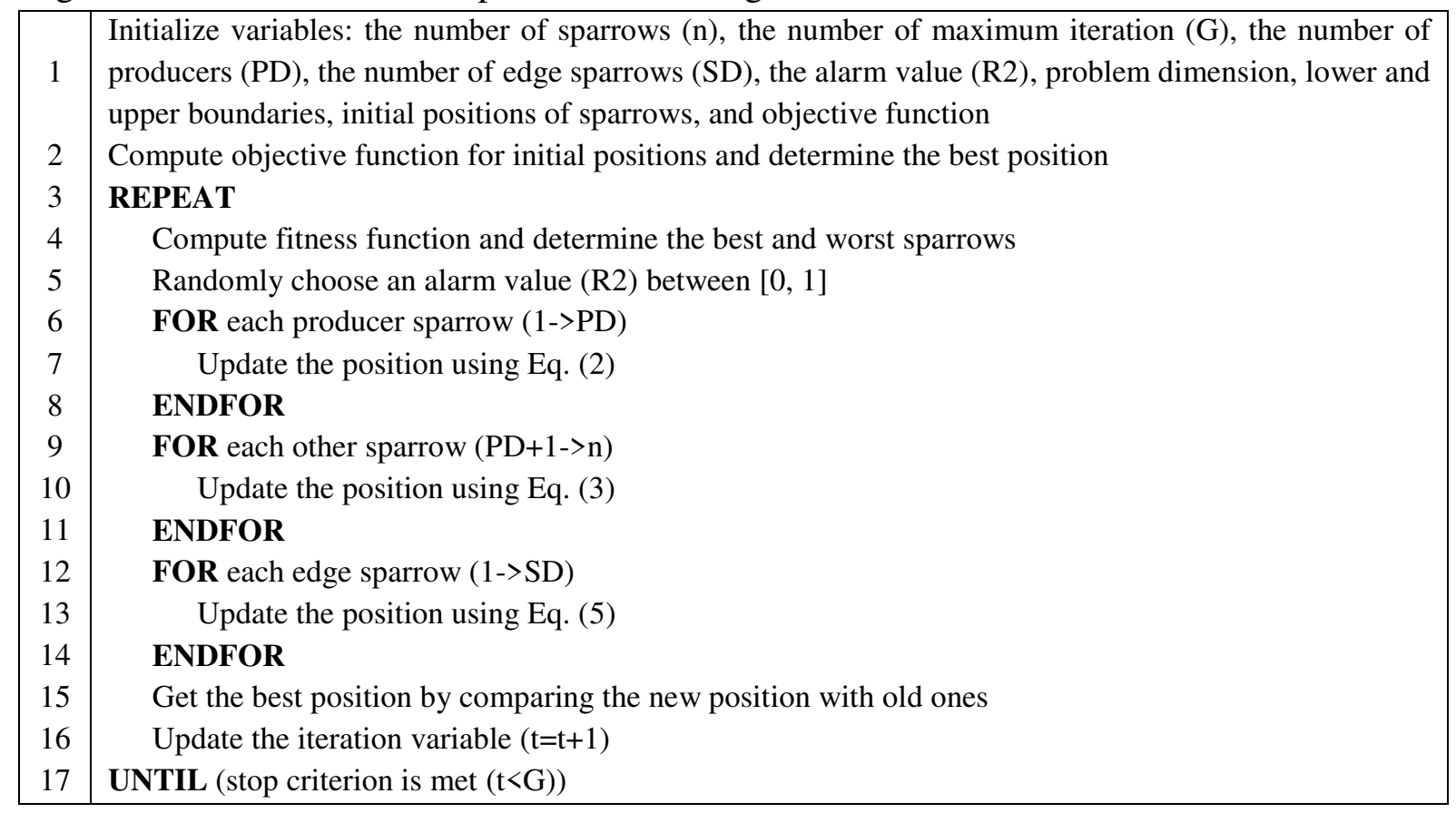

\subsection{Antenna Design and Optimization}

In this study, a microstrip-fed monopole microstrip antenna designed on a curved substrate structure for use in biomedical applications is illustrated in Figure 1. It was inspired by the study of Muntoni et al. [13] on the curved substrate idea. Polylactic acid (PLA) was used as substrate material, and a semi-cylinder-shaped structure was added to the center of the planar substrate 
design in the antenna design. The center point of the curved structure is positioned at the appropriate point in the z-axis to adjust the projected length of the radiating curved copper plane $\left(L_{C}\right)$. The material of the curved structure has been chosen the same as the main substrate material to ensure ease of production. The feed line, ground plane, and radiating curved patch were made using $35 \mu \mathrm{m}$ thick copper tape, and a $50 \Omega$ SMA port is used for feeding.

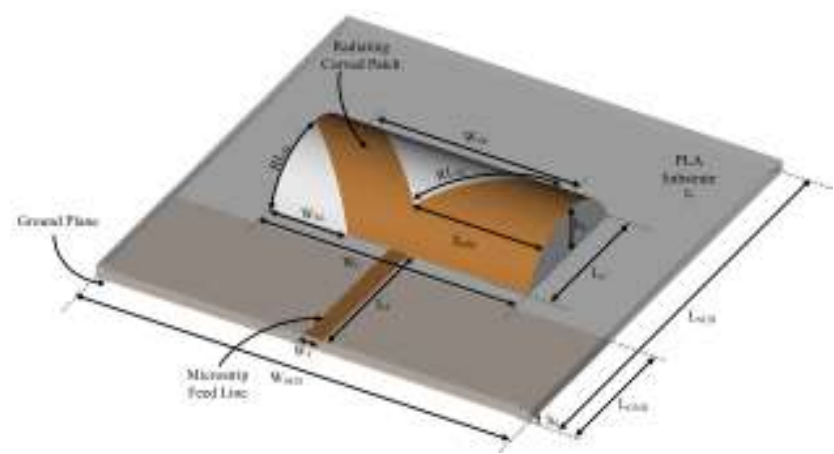

Figure 1. Perspective view of printed microstrip antenna designed on a curved substrate

The thickness of the substrate materials used in microstrip antennas is generally chosen to be smaller than the free-space wavelength $\left(\lambda_{0}\right)$. In this case, transverse magnetic (TM) field configurations are considered for MAs. For a rectangular microstrip antenna, the resonance frequency for $\mathrm{TM}_{\mathrm{mnp}}$ mode is defined by Equation (6) [1].

$$
\left(f_{r}\right)_{m n p}=\frac{v_{0}}{2 \pi \sqrt{\mu_{r} \varepsilon_{r}}} \sqrt{\left(\frac{m \pi}{h}\right)^{2}+\left(\frac{n \pi}{L}\right)^{2}+\left(\frac{p \pi}{W}\right)^{2}}
$$

The parameters $(m, n, p), v_{0}, \mu_{r}$, and $\varepsilon_{r}$ in Equation (6) represent the mode indices, the velocity of the electromagnetic wave in free space, magnetic permeability, and relative permittivity respectively. Substrate thickness, patch length, and patch width are defined by $h, L$, and $W$ parameters for the rectangular microstrip antenna. As can be seen from Equation (6), the resonant frequency of a conventional shaped microstrip antenna can be calculated easily. However, as the antenna design becomes more complex, it becomes difficult to calculate the resonant frequency directly, so computer-aided design and calculation software is used. In addition, as can be seen from the expression, the increase in the $h$ and $L$ parameters has a decreasing effect on the operating frequency of the antenna. The curved substrate structure used in this study has the effect of increasing the length of the copper plane that can be placed on it and increasing the bandwidth and lowering the resonance frequency thanks to its height. For a microstrip antenna to operate at the desired frequency, matching the antenna impedance and the free space impedance is required. An indication that impedance matching has occurred in microstrip antennas is defined by $\mathrm{S}_{11}$ as given in Equation (7).

$$
\left|S_{11}\right|=-20 \log \left(\frac{z_{L}-z_{0}}{z_{L}+z_{0}}\right)
$$

$z_{L}$ and $z_{0}$ in Equation (7) denote the characteristic impedance of the antenna and free-space, respectively. If the parameter $\left|S_{11}\right|$ is near or less than $-10 \mathrm{~dB}$, it indicates that the designed antenna can perform well in the desired frequency range. Accordingly, in order for the antenna designed in this study to perform well, the antenna dimensions that will ensure $\left|S_{11}\right|$ values in 
the desired frequency range to be at or below $-10 \mathrm{~dB}$ has been optimized by considering the cost function given in Equation (8) and (9).

$$
\begin{aligned}
& \text { CostCoeff }\left(f_{n}\right)= \begin{cases}0 & S_{11, s}<S_{11, d} \\
\left|S_{11, d}-S_{11, s}\right| & \text { otherwise }\end{cases} \\
& \text { CostFunc }=\frac{1}{N} \sum_{n=1}^{N} \operatorname{Cos} t \operatorname{Coeff}\left(f_{n}\right)
\end{aligned}
$$

The parameters $f_{n}, N, S_{11, s}$, and $S_{11, d}$ in Equations (8) and (9) represent the simulated $\mathrm{n}^{\text {th }}$ frequency, the total number of frequencies, the simulated $S_{11}$ value, and the desired $S_{11}$ value, respectively. The proposed curved microstrip antenna is modeled in the CST Microwave Studio, and the physical parameters are optimized utilizing the SpaSA algorithm to provide the desired $S_{11}$ characteristics of the antenna. The substrate was produced with 3D-printer technology using PLA material, and then the copper tape has adhered to the conductive parts. The values of the projected length and ground length parameters of the antenna are chosen to be around $0.21 \lambda \sim 0.215 \lambda . R L_{S L}, W_{S L}, R L_{S U}, X_{S M}, W_{S U}, L_{G N D}$, and $L_{F}$ parameters used in the proposed antenna design are defined as the unknowns of the optimization problem. The physical parameters and their values are given in Table 2.

Table 2. Physical parameters and their values of the proposed antenna

\begin{tabular}{lclc}
\hline Parameter & Value $(\mathbf{m m})$ & Parameter & Value $(\mathbf{m m})$ \\
\hline $\mathrm{W}_{\mathrm{SUB}}$ & 71.50 & $\mathrm{~W}_{\mathrm{C}}$ & 42.43 \\
$\mathrm{~L}_{\mathrm{SUB}}$ & 71.50 & $\mathrm{~L}_{\mathrm{C}}$ & 22.50 \\
$\mathrm{~L}_{\mathrm{GND}}$ & 23.10 & $\mathrm{~W}_{\mathrm{SL}}$ & 12.73 \\
$\mathrm{~h}_{\mathrm{S}}$ & 2.00 & $\mathrm{RL}_{\mathrm{SL}}$ & 12.73 \\
$\mathrm{~h}_{\mathrm{C}}$ & 7.82 & $\mathrm{X}_{\mathrm{SM}}$ & 21.22 \\
$\mathrm{~W}_{\mathrm{F}}$ & 3.00 & $\mathrm{~W}_{\mathrm{SU}}$ & 36.43 \\
$\mathrm{~L}_{\mathrm{F}}$ & 24.50 & $\mathrm{RL}_{\mathrm{SU}}$ & 25.76 \\
\hline
\end{tabular}

In order to compare the performance of the antenna proposed in this study, five additional microstrip antennas given in Figure 2 (a) - (f) were designed, and the results of these antennas in terms of $\left|S_{11}\right|$, VSWR, gain, and radiation pattern were obtained between $2 \mathrm{GHz}$ and $12 \mathrm{GHz}$.

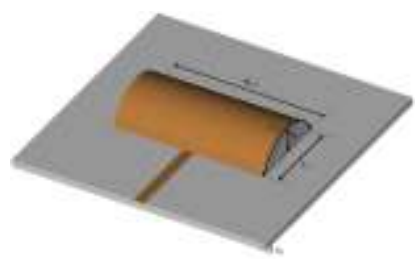

(a)

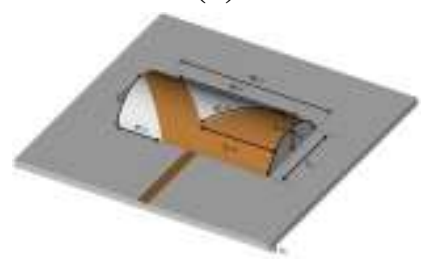

(d)

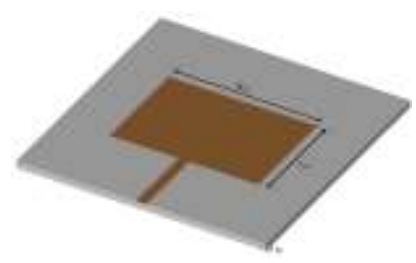

(b)

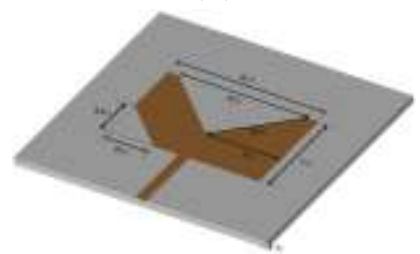

(e)

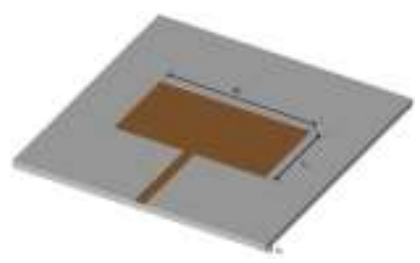

(c)

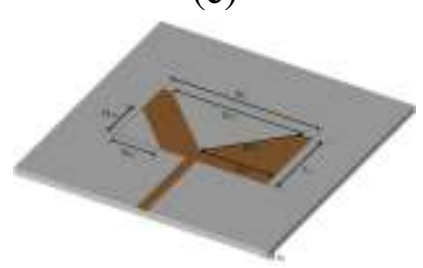

(f)

Figure 2. Perspective views of (a) curved MA, (b) flat MA \#1 of curved MA in (a), (c) flat MA \#3 of curved MA in (a), (d) proposed curved MA, (e) flat MA \#2 of proposed curved MA in (d), (f) flat MA \#4 of proposed curved MA in (d) 
For this purpose, initially, a curved rectangular microstrip antenna with microstrip line feed was designed, as shown in Figure 2 (a). After that, triangular slots were formed on this antenna, as in Figure 2 (d). The antenna design in Figure 2 (b) is obtained by converting the curved radiating plane to a flat design for a flat substrate structure. The radiating plane dimensions of the antenna given in Figure 2 (b) were chosen equal to the angular dimensions of the antenna given in Figure 2 (a). In order to make a different comparison in showing the effect of the curved substrate structure, the antenna in Figure 2 (c) was designed to be in the dimensions obtained by projecting the curved radiating plane. In order to make comparisons for the antenna with slots, antennas containing triangular slots given in Figure 2 (e) and Figure 2 (f) were designed to be equivalent to the antenna given in Figure 2 (d). The flat dimensions used in Figure 2 (e) are precisely equal to the angular dimensions of the antenna given in Figure 2 (d), but the dimensions used in Figure 2 (f) are determined to be equal to the projections of the antenna dimensions given in Figure 2 (d).

\subsection{Manufacturing the Proposed Antenna}

The CST Microwave Studio environment was used to design and simulate the antenna, and the SpaSA algorithm was used to optimize the dimensions. The curved PLA substrate was printed using a commercial Creality Ender 3 Pro printer, as shown in Figure 3 (a). The bed and nozzle temperatures were set to $60^{\circ} \mathrm{C}$ and $205^{\circ} \mathrm{C}$, respectively, and an intermediate printhead speed of $50 \mathrm{~mm} / \mathrm{s}$ was chosen. A copper tape was glued to the front and back sides of the antenna for the conductive element after the substrate was manufactured, as shown in Figure 3 (b) and (c). Keysight N5224A PNA microwave network analyzer was used to test antennas in the $2 \mathrm{GHz}$ to $12 \mathrm{GHz}$ frequency range. The PNA was calibrated before the measurement with a calibration package that included a short circuit, open circuit, and loading apparatus. Following the calibration procedure, the manufactured antennas were mounted to the PNA, and the Sparameter measurements were obtained.

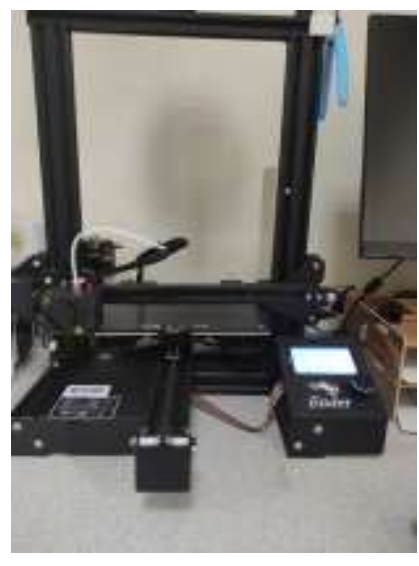

(a)

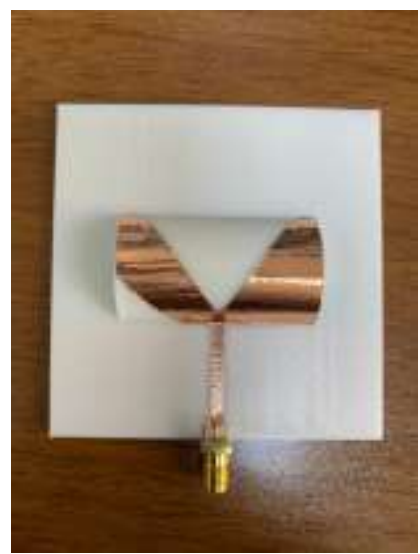

(b)

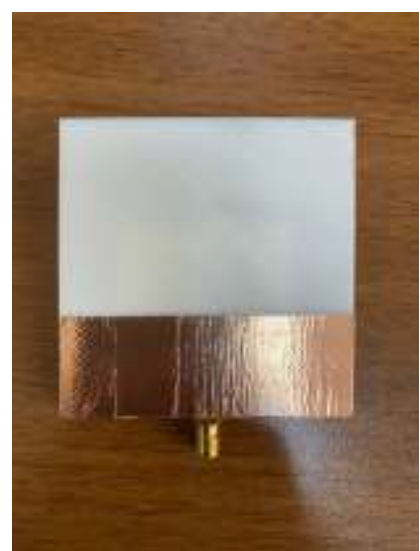

(c)

Figure 3. (a) 3D printer, (b) the top view and (c) the bottom view of the printed curved monopole microstrip antenna.

It can be easily modified to be used in more complex applications by changing the antenna dimension. Figure 3 shows the antenna terminals with an SMA connector soldered to them. The positive pin of the connector is soldered to the conductive copper patch on the front side, which serves as a positive terminal, and the negative pin is soldered to the conductive copper patch on the backside, which serves as a negative terminal. 


\section{Results}

The relative permittivity of a material depends on the frequency expressed by two parts, the real part, and the imaginary part, as given in Equation (10).

$$
\varepsilon_{r}(w)=\varepsilon_{r}^{\prime}(w)-i \varepsilon_{r}^{\prime \prime}(w)
$$

The dielectric constant of the PLA material used as the substrate material of the designed antenna in this study was measured in the range of $1 \mathrm{GHz}$ to $10 \mathrm{GHz}$. The real and imaginary parts and amplitude of the measured dielectric constant are given in Figure 4.

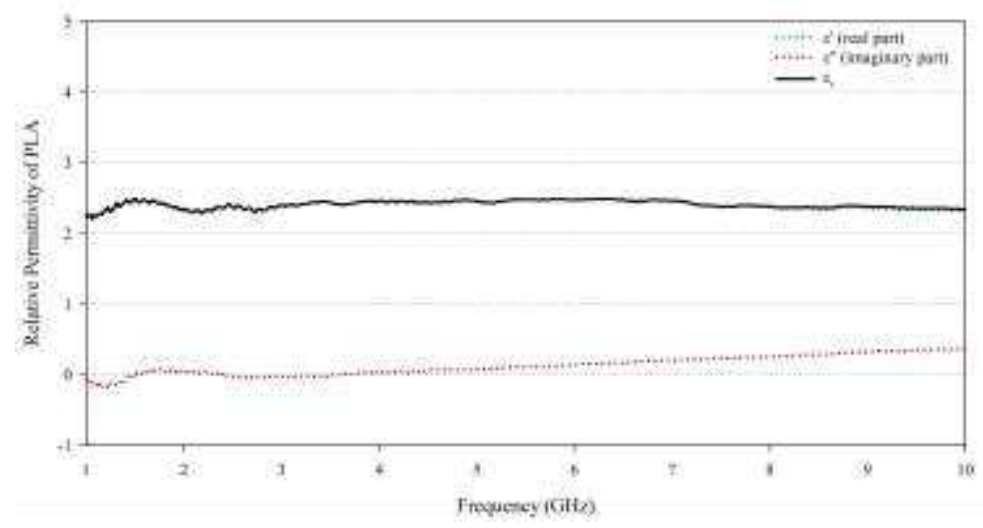

Figure 4. Relative permittivity curve of PLA material.

The SpaSA algorithm was used to optimize $R L_{S L}, W_{S L}, R L_{S U}, X_{S M}, W_{S U}, L_{G N D}$, and $L_{F}$ parameters in the proposed design in Figure 2 (d), and the resulting designs were simulated using CST MWS Studio software. Figure 5 (a) shows the $\left|S_{11}\right|$ curves obtained from the simulation of six different antennas designed in this study. The curves given with dotted line and solid line in the figure represent the $S_{11}$ results for antennas that do not contain slots and that contain slots, respectively. The simulated VSWR results of the considered antenna designs are given in Figure 5 (b).

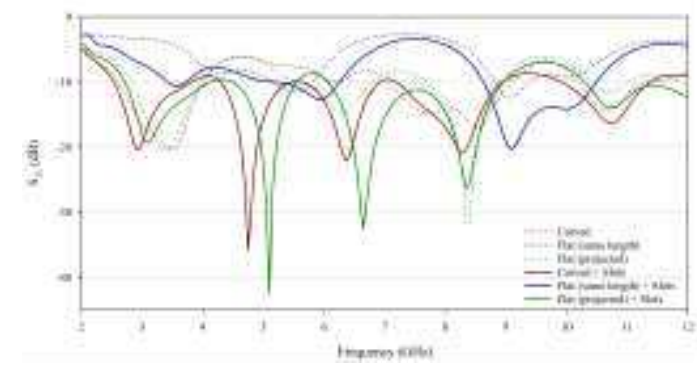

(a)

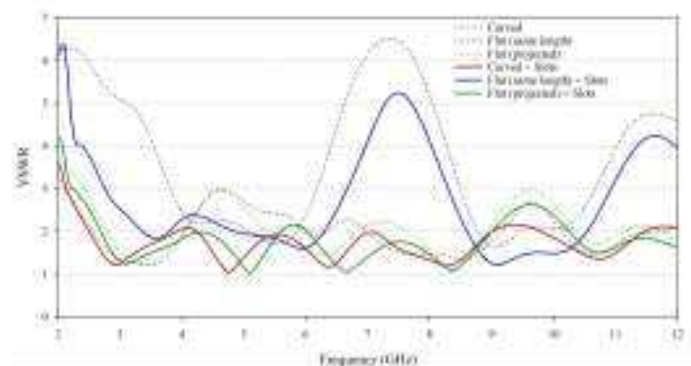

(b)

Figure 5. Comparison of simulated (a) $\left|S_{11}\right|$ parameter and (b) VSWR curves of the proposed MA.

The simulated gain values of the designed antennas in the frequency range of $2 \mathrm{GHz}$ to $12 \mathrm{GHz}$ are presented in Figure 6. 


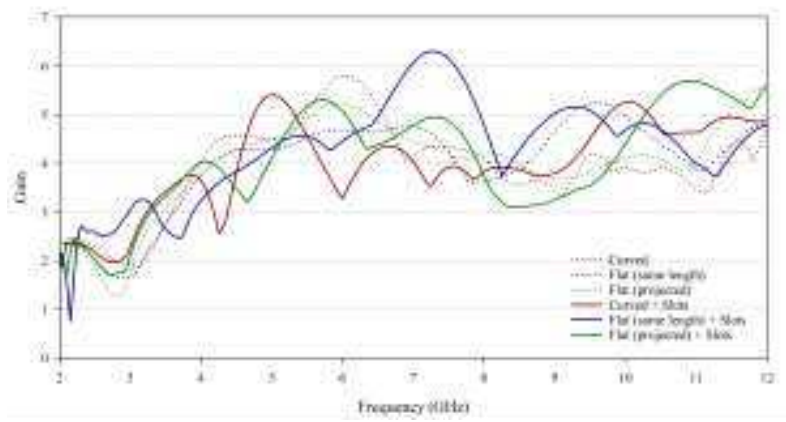

Figure 6. Comparison of simulated gain parameter curves of the proposed MA.

The simulation results for the antenna designs given in Figure 2 show that the curved microstrip antenna with a triangular slot performs well over the desired frequency range. Therefore, this antenna was manufactured using a $3 \mathrm{D}$ printer, and $S_{11}$ measurements were taken using Keysight N5224A PNA Microwave Network Analyzer. The $S_{11}$ results obtained from simulation and measurement of the proposed curved microstrip antenna are given in Figure 7.

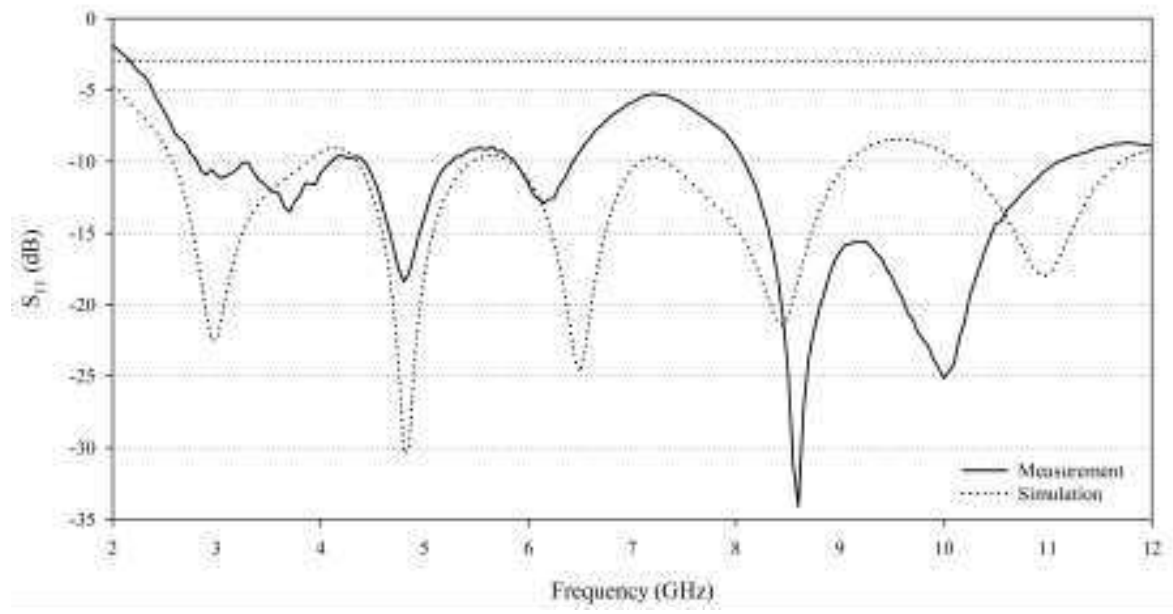

Figure 7. Simulated and measured $\left|S_{11}\right|$ parameter curves of the proposed MA.

Simulated surface current images of the proposed antenna for $4.8 \mathrm{GHz}$ and $8.6 \mathrm{GHz}$ frequencies are given in Figure 8.

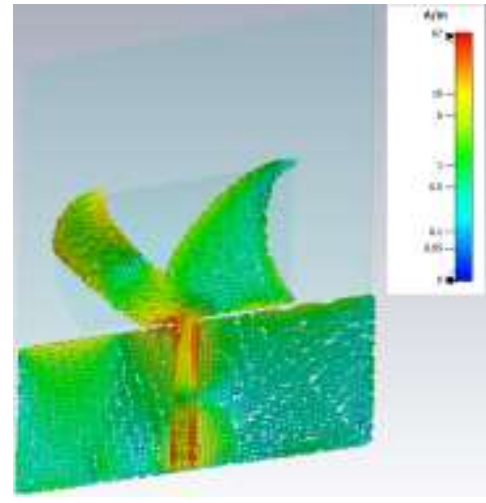

(a)

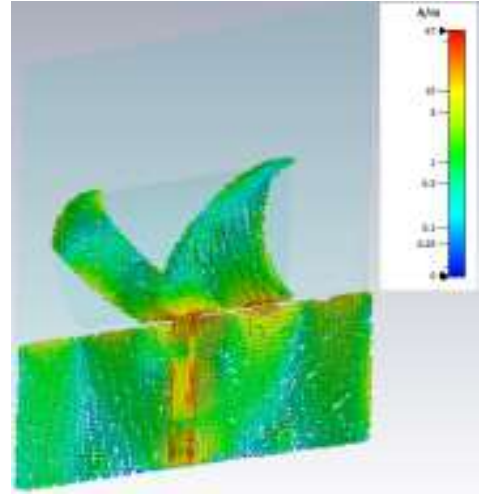

(b)

Figure 8. Simulated surface current images of the proposed MA for (a) $4.8 \mathrm{GHz}$ and (b) 8.6 $\mathrm{GHz}$. 
The simulated radiation patterns at $4.8 \mathrm{GHz}$ and $8.6 \mathrm{GHz}$ frequencies of the proposed curved microstrip antenna are given in Figure 9.

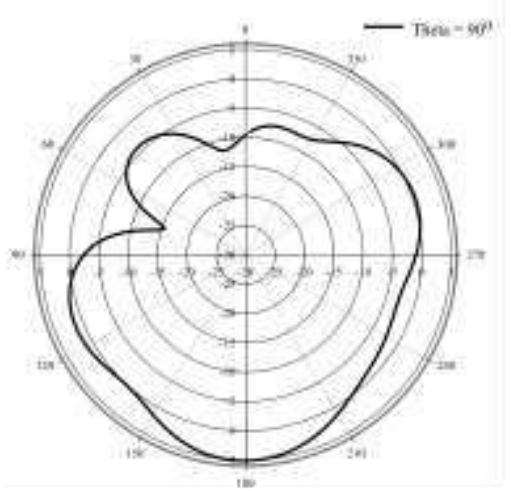

(a)

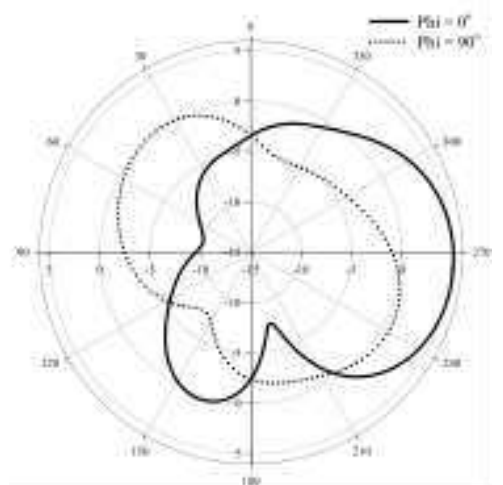

(c)

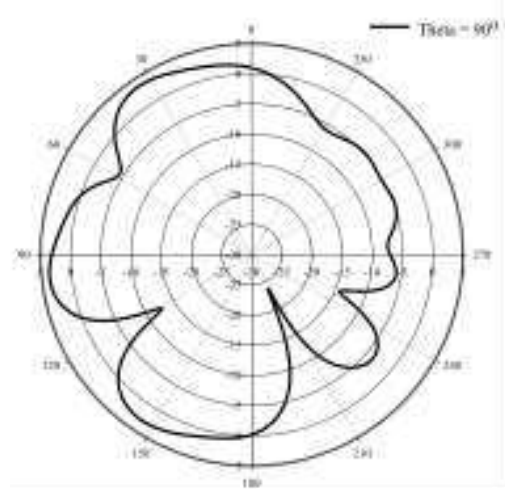

(b)

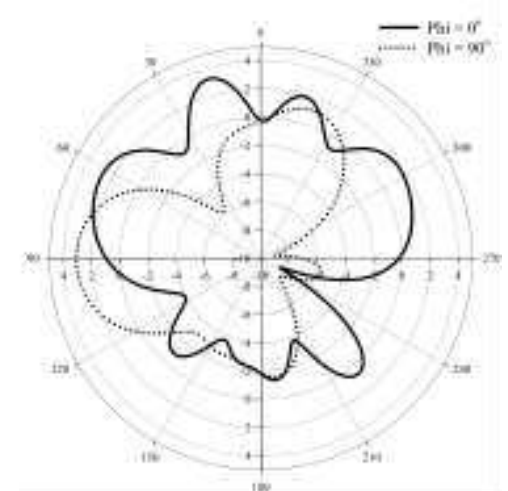

(d)

Figure 9. Simulated radiation patterns of the proposed MA for (a) theta $=90^{\circ}(x-y$ plane) at $4.8 \mathrm{GHz}$, (b) theta $=90^{\circ}(x-y$ plane $)$ at $8.6 \mathrm{GHz}$, (c) phi $=0^{\circ}(x-z$ plane $)$ and phi $=90^{\circ}(x-y$ plane) at $4.8 \mathrm{GHz}$ and $(\mathrm{d}) \mathrm{phi}=0^{\circ}(x-z$ plane $)$ and phi $=90^{\circ}(x-y$ plane $)$ at $4.8 \mathrm{GHz}$.

\section{Discussion}

As seen in Figure 4, the imaginary part of the dielectric constant increases monotonically from -0.1969 to 0.3670 , while the real part varies between 2.1975 and 2.4956, as shown in Figure 4 . The calculated amplitude of the dielectric constant by Equation (10) varies between $1 \mathrm{GHz}$ and $10 \mathrm{GHz}$ frequencies, with an average value of 2.4119 . It can be seen from the figure that the dielectric constant of the substrate fluctuates slightly between $1 \mathrm{GHz}$ and $2 \mathrm{GHz}$, while it remains relatively constant in the frequency band between $2 \mathrm{GHz}$ and $10 \mathrm{GHz}$. The value 2.54 proposed in the literature was used as a standard in the antenna design process.

The SpaSA algorithm was used to optimize $R L_{S L}, W_{S L}, R L_{S U}, X_{S M}, W_{S U}, L_{G N D}$, and $L_{F}$ parameters of the proposed structure in Figure 2 (d), and the resulting designs were simulated using CST MWS Studio software. Figure 5 (a) shows the $\left|S_{11}\right|$ curves obtained from the simulation of six different antennas designed in this study. The curves given with dotted line and solid line in the figure represent the $S_{11}$ results for antennas that do not contain slots and that contain slots, respectively. The results of the curved radiating plane with slots and the results of the flat antenna constructed using the exact dimensions of this antenna vary significantly. The comparison shows that the curved structure performs better than the flat structure. The $S_{11}$ results of the slotted flat antenna created by projecting the dimensions of the curved design show a performance that is comparable to the curved structure, but the curved slotted antenna offers the best result. Figure 5 (a) shows that opening two triangular-shaped slots in the copper 
plane of the curved antenna improved radiation efficiency from $4 \mathrm{GHz}$ to $7 \mathrm{GHz}$ and from 9 $\mathrm{GHz}$ to $10 \mathrm{GHz}$. One of the essential parameters that give information about the performance of a microstrip antenna is the voltage standing wave ratio (VSWR). A VSWR of less than two means that the antenna is performing well. As seen in Figure 5 (b), the simulated VSWR of the proposed antenna ranges between 2 and 3. Comparing Figure 5 (a) and (b) shows that the VSWR results confirm the $S_{11}$ results.

The proposed antenna provides a higher gain than the other antennas for frequencies ranging from $2 \mathrm{GHz}$ to $4 \mathrm{GHz}$, although it has the lowest gain for frequencies ranging from $4 \mathrm{GHz}$ to $4.5 \mathrm{GHz}$ and $5 \mathrm{GHz}$ to $8 \mathrm{GHz}$, as shown in Figure 6. The proposed antenna has a relatively stable gain in the range of $7 \mathrm{GHz}$ to $9 \mathrm{GHz}$ and an increasing gain from $9 \mathrm{GHz}$ to $12 \mathrm{GHz}$. Although the designed antennas show low or high performance in terms of gain, the gains of the antennas proposed in this study are in the range of $1 \mathrm{dBi}$ to $3 \mathrm{dBi}$ for the $2 \mathrm{GHz}$ to $4 \mathrm{GHz}$ frequency band and $3 \mathrm{dBi}$ to $6 \mathrm{dBi}$ for the $4 \mathrm{GHz}$ and $12 \mathrm{GHz}$ frequency bands.

As seen in Figure 7 , while the $S_{11}$ curves for measurement and simulation show a similar downward trend between $2 \mathrm{GHz}$ and $3.5 \mathrm{GHz}$, it is seen that there is a mismatch in the frequency band of $2.7 \mathrm{GHz}$ and $4 \mathrm{GHz}$ and the simulation results are better than the measurement results. It can be said that the simulation results show a good performance in the $6 \mathrm{GHz}$ and $8.3 \mathrm{GHz}$ frequency bands while there is a great harmony between the curves in the $4 \mathrm{GHz}$ and $6 \mathrm{GHz}$ frequency bands. The measurement values are higher than the $-10 \mathrm{~dB}$ reference in this frequency range. Measurement results between $8.3 \mathrm{GHz}$ and $11 \mathrm{GHz}$ provide better performance than simulation results, while measurement and simulation results are in harmony with each other in the frequency range of $11 \mathrm{GHz}$ and $12 \mathrm{GHz}$. Although the measurement result in the $6.3 \mathrm{GHz}$ to $8 \mathrm{GHz}$ frequency range is higher than $-10 \mathrm{~dB}$ reference, it has reasonable operating efficiency because it is lower than $-5 \mathrm{~dB}$.

As shown in Figure 8, the surface current at $4.8 \mathrm{GHz}$ is concentrated along the line edges of the microstrip line, around the junction point of the microstrip line and the radiating patch, and on the left branch edges, while at $8.6 \mathrm{GHz}$, the junction points of the feed and curved radiating patch, slot edges on the left branch and concentrated around the lower level of the right branch. The surface current distribution indicates that the slot formed in the lower-left corner is effective at low frequencies, while the right branch is effective at higher frequencies. Furthermore, the significance of the gap between the ground plane and the curved radiating patch can be seen, especially in Figure 8 (b).

The proposed antenna has approximately bi-directional radiation performance at lower frequencies, as seen from Figures 9 (a) and (c). However, as expected, the side lobes appear in higher frequencies, causing distortions in radiation patterns.

\section{Conclusion}

This study aims to develop a microstrip antenna with a broad bandwidth capable of operating at frequencies between 3 and $12 \mathrm{GHz}$. For this purpose, a curved substrate structure was used to propose a triangular slotted microstrip-fed monopole MA configuration. The sparrow search algorithm (SpaSA) was used to estimate the antenna dimensions for the desired operating frequencies optimally. To compare the efficiency of the proposed antenna, five additional antenna designs were modeled, and their simulation results were compared. The results indicate that the proposed antenna could be an excellent candidate for biomedical applications.

\section{Acknowledgment}

We would like to thank Karamanoğlu Mehmetbet University Engineering Faculty Electrical and Electronics Engineering Department for their support in the measurements. 


\section{References}

1. Balanis CA Antenna Theory: Analysis and Design. 2005

2. Zhu Y, Li J, Zhang X, et al (2020) A 3-D Printed Spherical Antenna With Bandwidth Enhancement Under Operation of Dual Resonance. IEEE Access 8:19345-19352. https://doi.org/10.1109/access.2020.2968187

3. Gu C, Gao S, Fusco V, et al (2020) A D-Band 3D-Printed Antenna. IEEE Trans Terahertz Sci Technol 10:. https://doi.org/10.1109/TTHZ.2020.2986650

4. $\quad \mathrm{Su} \mathrm{W}, \mathrm{Wu} \mathrm{Z}$, Fang Y, et al (2017) 3D printed wearable flexible SIW and microfluidics sensors for Internet of Things and smart health applications. In: IEEE MTT-S International Microwave Symposium Digest

5. He H, Akbari M, Sydanheimo L, et al (2017) 3D-printed graphene and stretchable antennas for wearable RFID applications. In: 2017 International Symposium on Antennas and Propagation, ISAP 2017

6. Farooqui MF, Shamim A (2016) Low Cost Inkjet Printed Smart Bandage for Wireless Monitoring of Chronic Wounds. Sci Rep 6:. https://doi.org/10.1038/srep28949

7. Zada M, Shah IA, Yoo H (2020) Metamaterial-Loaded Compact High-Gain Dual-Band Circularly Polarized Implantable Antenna System for Multiple Biomedical Applications. IEEE Trans Antennas Propag 68:.

https://doi.org/10.1109/TAP.2019.2938573

8. Baki AKM, Rahman MN, Mondal SK (2019) Analysis of Performance-Improvement of Microstrip Antenna at $2.45 \mathrm{GHz}$ through Inset Feed Method. In: 1st International Conference on Advances in Science, Engineering and Robotics Technology 2019, ICASERT 2019

9. Striker R, Mitra Di, Braaten BD (2020) Permittivity of 3D Printed NinjaFlex Filament for use in Conformal Antenna Designs up to $20 \mathrm{GHz}$. In: IEEE International Conference on Electro Information Technology

10. Colella R, Catarinucci L, Michel A (2020) Circularly polarized antenna in 3d printing technology to feed a wearable fully-integrated WiFi-RFID reader for biomedical applications. In: 2020 International Workshop on Antenna Technology, iWAT 2020

11. Colella R, Chietera FP, Montagna F, et al (2020) Customizing 3D-Printing for Electromagnetics to Design Enhanced RFID Antennas. IEEE J Radio Freq Identif 4:. https://doi.org/10.1109/jrfid.2020.3001043

12. Kirtania SG, Elger AW, Hasan MR, et al (2020) Flexible antennas: A review. Micromachines 11

13. Muntoni G, Montisci G, Casula GA, et al (2020) A Curved 3-D Printed Microstrip Patch Antenna Layout for Bandwidth Enhancement and Size Reduction. IEEE Antennas Wirel Propag Lett 19:1118-1122. https://doi.org/10.1109/lawp.2020.2990944

14. Lomakin K, Sippel M, Ullmann I, et al (2020) 3D Printed Helix Antenna for 77GHz. In: 14th European Conference on Antennas and Propagation, EuCAP 2020

15. Sarjoghian S, Alfadhl Y, Chen X, Parini CG (2021) A 3-D-Printed High-Dielectric Materials-Filled Pyramidal Double-Ridged Horn Antenna for Abdominal Fat Measurement System. IEEE Trans Antennas Propag 69:64-73. https://doi.org/10.1109/tap.2020.3008653

16. Raniszewski A, Slojewska B, Piasecki P, Strycharz J (2020) Miniaturized 3D-printed Antenna Realizations for Cylindrical Surface Mounting. In: 2020 23rd International Microwave and Radar Conference, MIKON 2020

17. Njogu P, Sanz-Izquierdo B, Elibiary A, et al (2020) 3D Printed Fingernail Antennas for 5G Applications. IEEE Access 8:. https://doi.org/10.1109/ACCESS.2020.3043045

18. Mitra D, Striker R, Cleveland J, et al (2021) A 3D Printed Microstrip Patch Antenna 
using Electrifi Filament for In-Space Manufacturing. In: 2021 United States National Committee of URSI National Radio Science Meeting, USNC-URSI NRSM 2021 Proceedings

19. Belen A, Güneș F, Mahouti P, Palandöken M (2020) A novel design of high performance multilayered cylindrical dielectric lens antenna using $3 \mathrm{D}$ printing technology. Int J RF Microw Comput Eng 30:. https://doi.org/10.1002/mmce.21988

20. Moscato S, Bahr R, Le T, et al (2016) Infill-Dependent 3-D-Printed Material Based on NinjaFlex Filament for Antenna Applications. IEEE Antennas Wirel Propag Lett 15:. https://doi.org/10.1109/LAWP.2016.2516101

21. Yadav A, Singh VK, Bhoi AK, et al (2020) Wireless body area networks: UWB wearable textile antenna for telemedicine and mobile health systems. Micromachines 11:. https://doi.org/10.3390/MI11060558

22. Simorangkir RBVB, Kiourti A, Esselle KP (2018) UWB Wearable Antenna with a Full Ground Plane Based on PDMS-Embedded Conductive Fabric. IEEE Antennas Wirel Propag Lett 17:493-496. https://doi.org/10.1109/LAWP.2018.2797251

23. Brar RS, Singhal S, Singh AK (2016) Rotated quadrilateral dipole UWB antenna for wireless communication. Prog Electromagn Res C 66:117-128. https://doi.org/10.2528/PIERC16051402

24. Sun Y, Cheung SW, Yuk TI (2014) Design of a textile ultra-wideband antenna with stable performance for body-centric wireless communications. IET Microwaves, Antennas Propag 8:1363-1375. https://doi.org/10.1049/iet-map.2013.0658

25. Fang R, Song R, Zhao X, et al (2020) Compact and low-profile uwb antenna based on graphene-assembled films for wearable applications. Sensors (Switzerland) 20:2-11. https://doi.org/10.3390/s20092552

26. Xue J, Shen B (2020) A novel swarm intelligence optimization approach: sparrow search algorithm. Syst Sci Control Eng 8:.

https://doi.org/10.1080/21642583.2019.1708830 


\section{Figures}

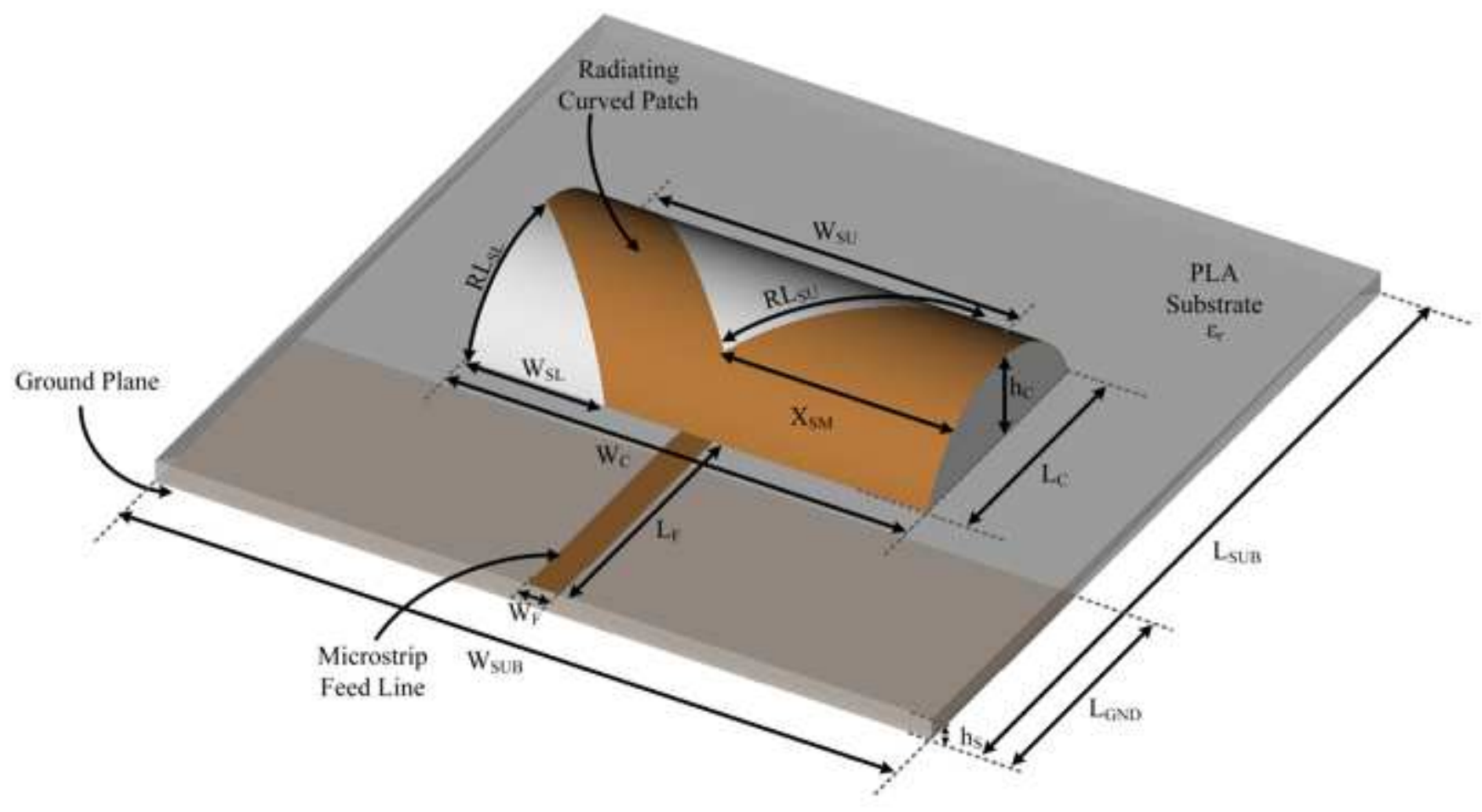

Figure 1

Perspective view of printed microstrip antenna designed on a curved substrate

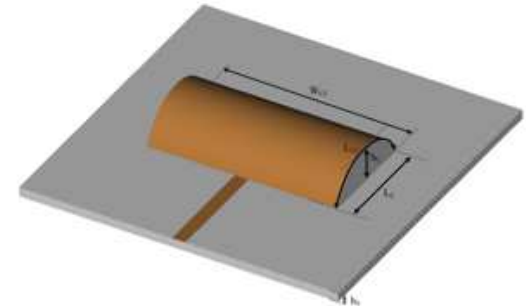

(a)

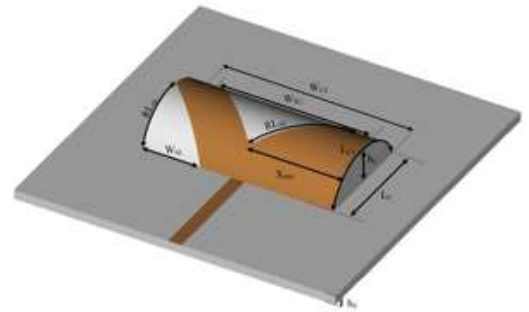

(d)

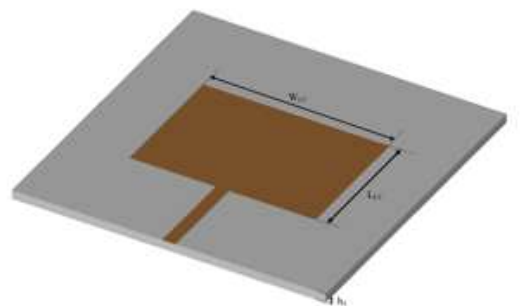

(b)

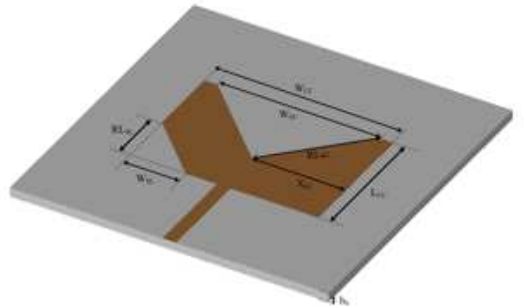

(e)

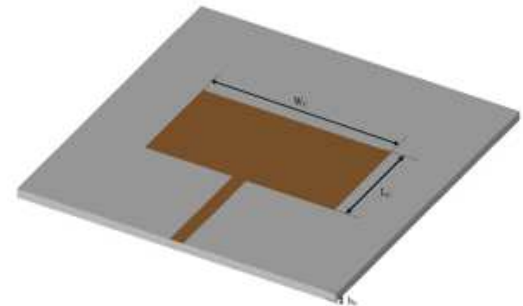

(c)

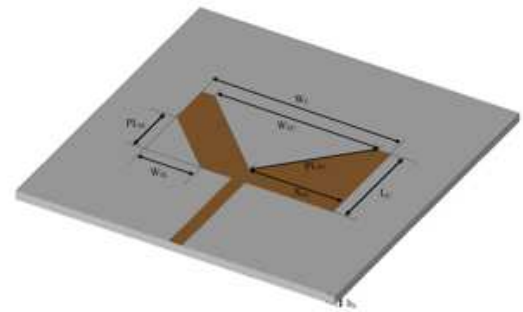

(f)

\section{Figure 2}

Perspective views of (a) curved MA, (b) flat MA \#1 of curved MA in (a), (c) flat MA \#3 of curved MA in (a), (d) proposed curved MA, (e) flat MA \#2 of proposed curved MA in (d), (f) flat MA \#4 of proposed curved 
MA in (d)

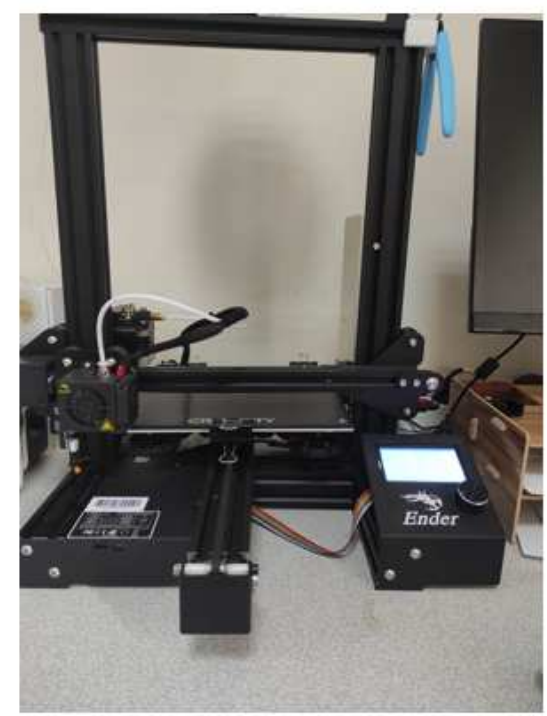

(a)

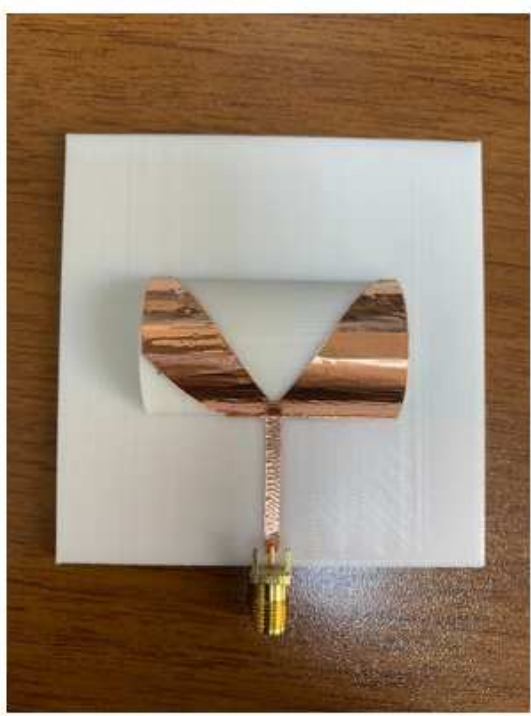

(b)

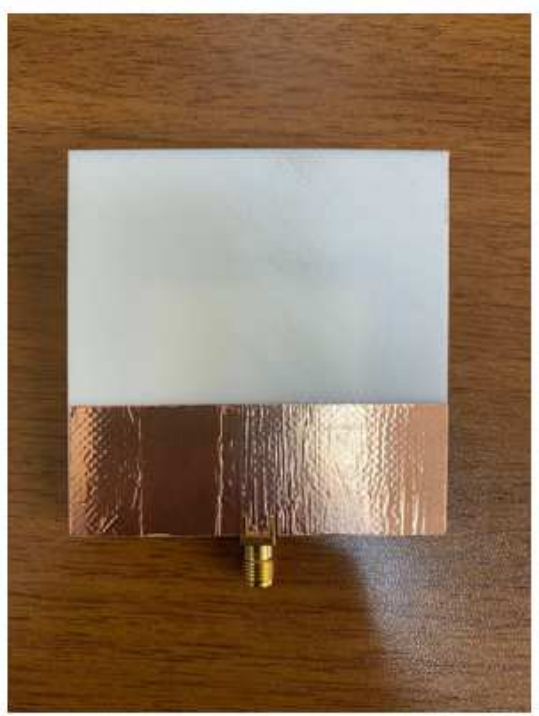

(c)

Figure 3

(a) 3D printer, (b) the top view and (c) the bottom view of the printed curved monopole microstrip antenna.

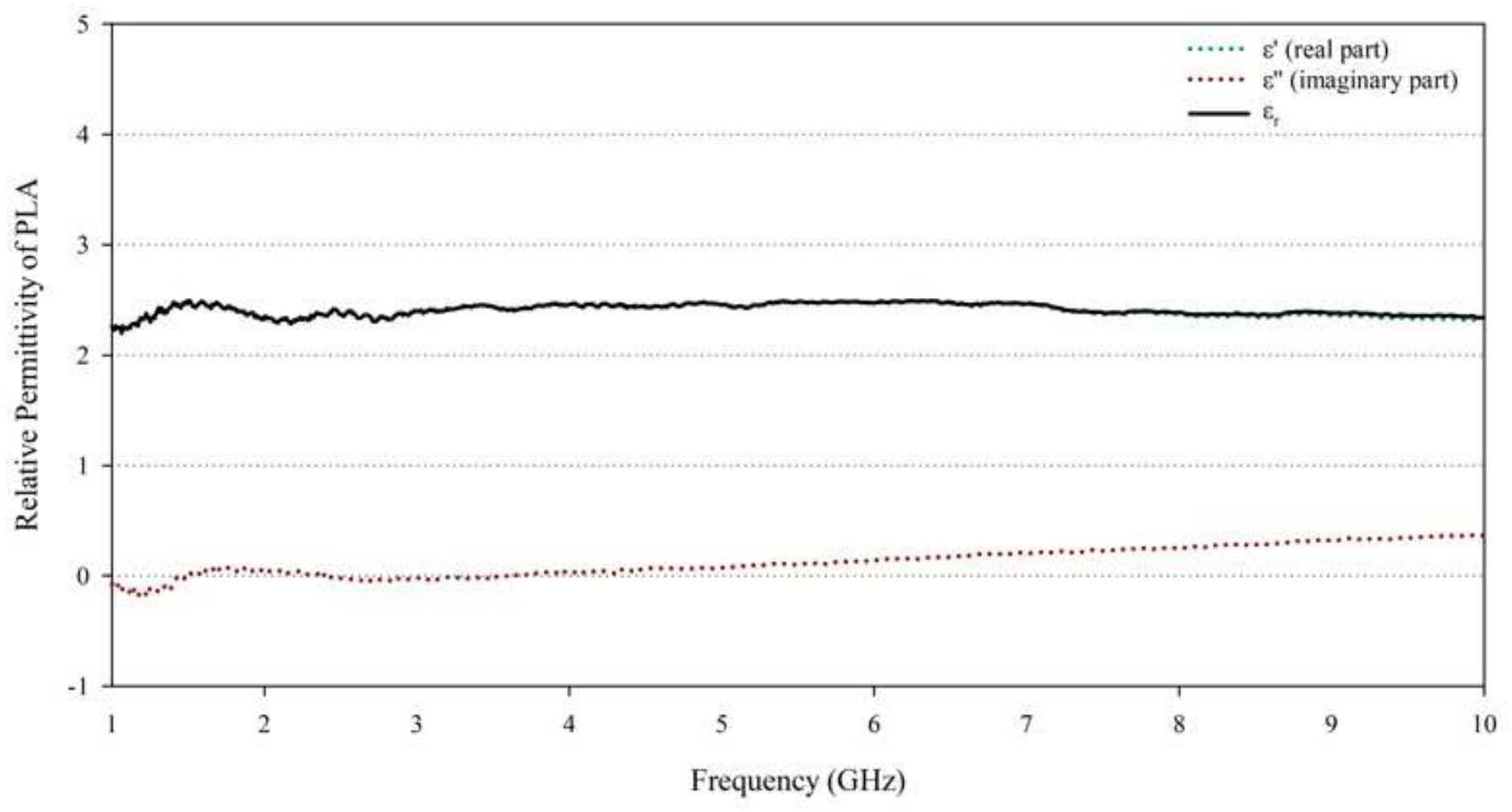

Figure 4

Relative permittivity curve of PLA material. 


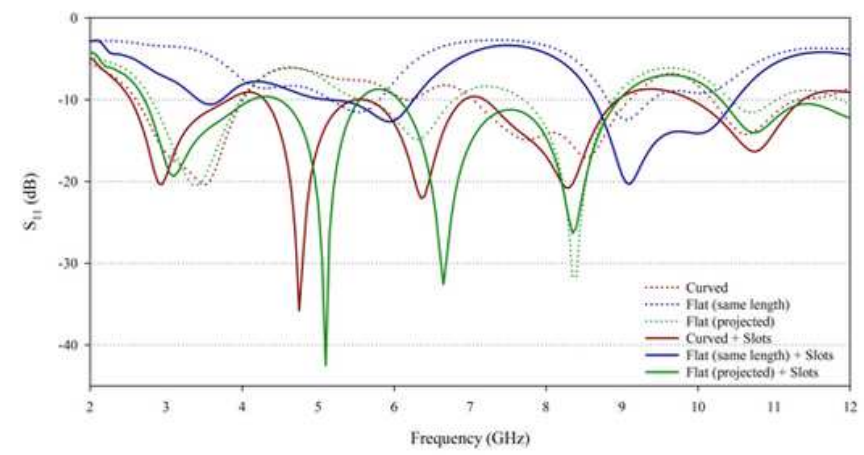

(a)

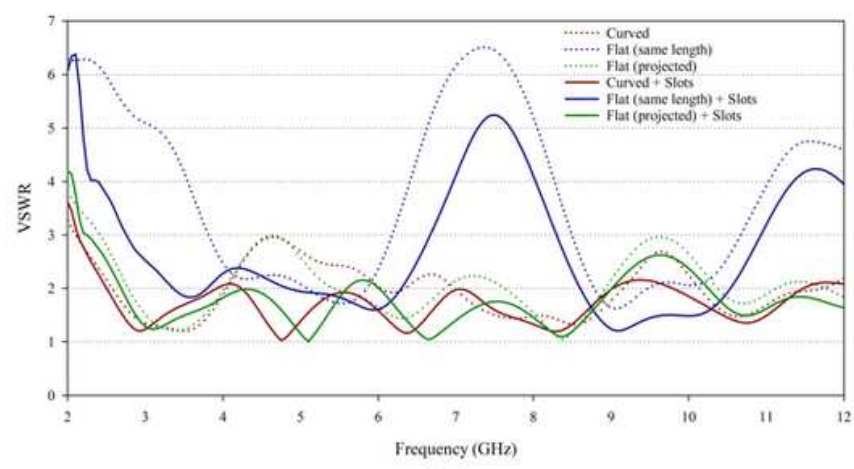

(b)

Figure 5

Comparison of simulated (a) |S11| parameter and (b) VSWR curves of the proposed MA.

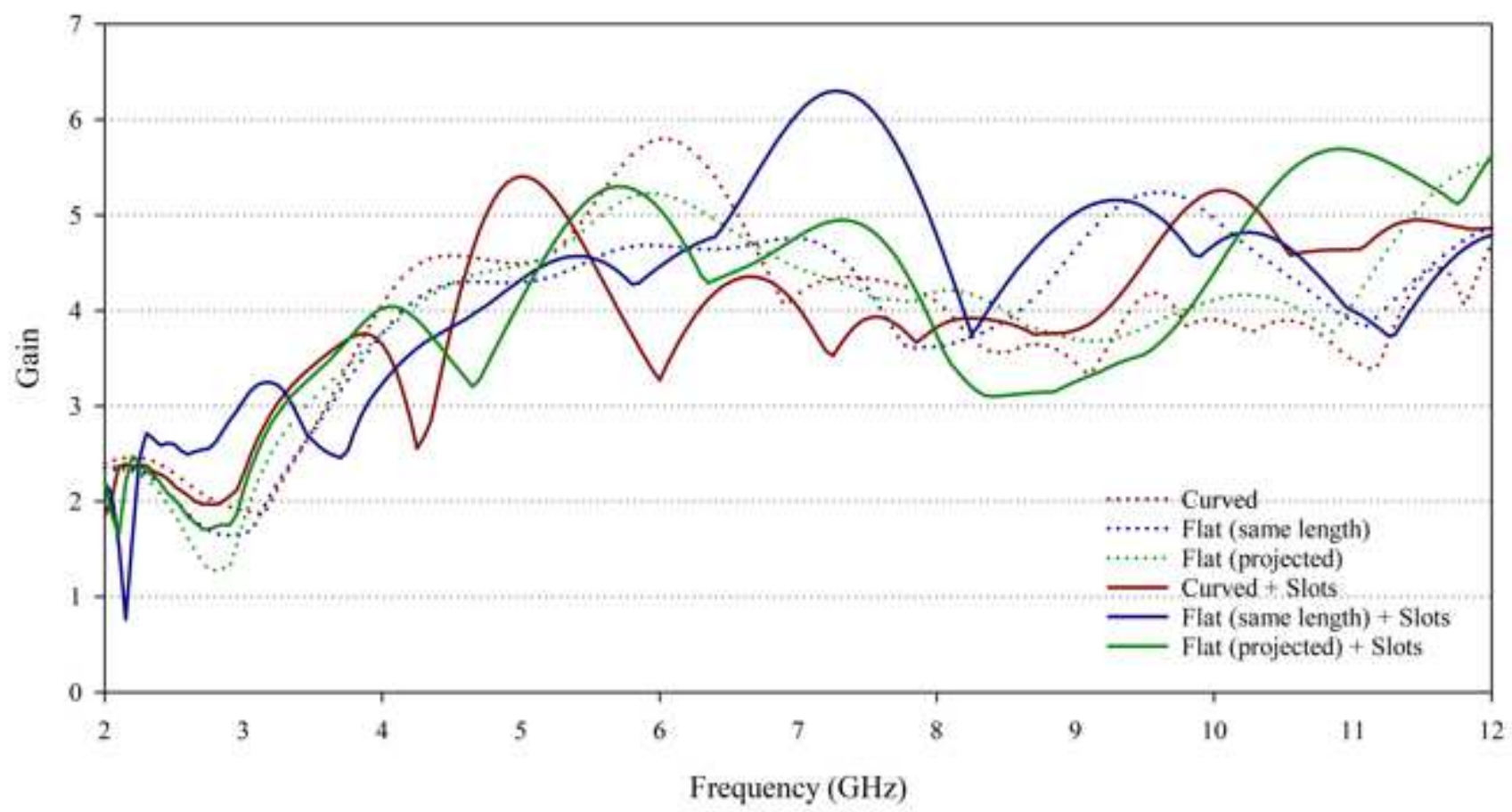

Figure 6

Comparison of simulated gain parameter curves of the proposed MA. 


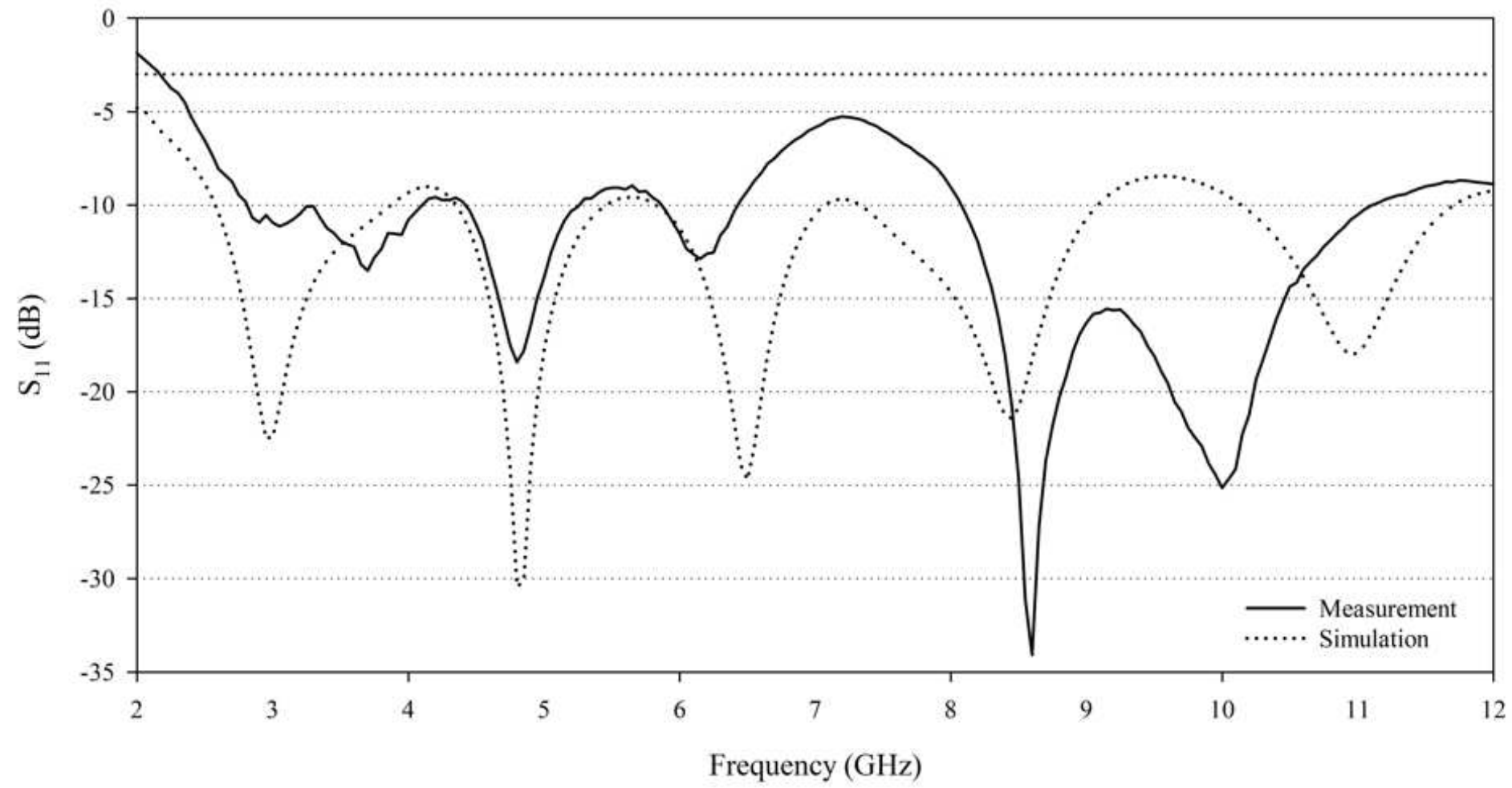

Figure 7

Simulated and measured |S11| parameter curves of the proposed MA.

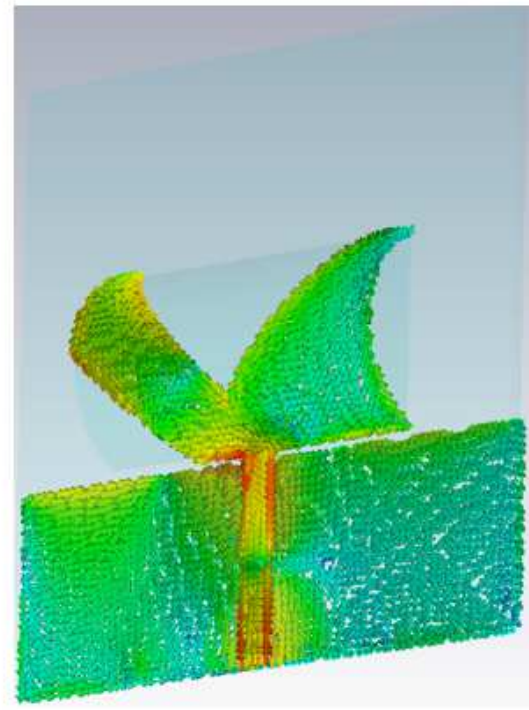

(a)

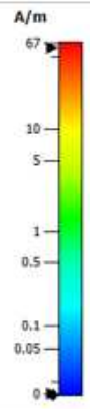

\section{Figure 8}

Simulated surface current images of the proposed MA for (a) $4.8 \mathrm{GHz}$ and (b) $8.6 \mathrm{GHz}$. 


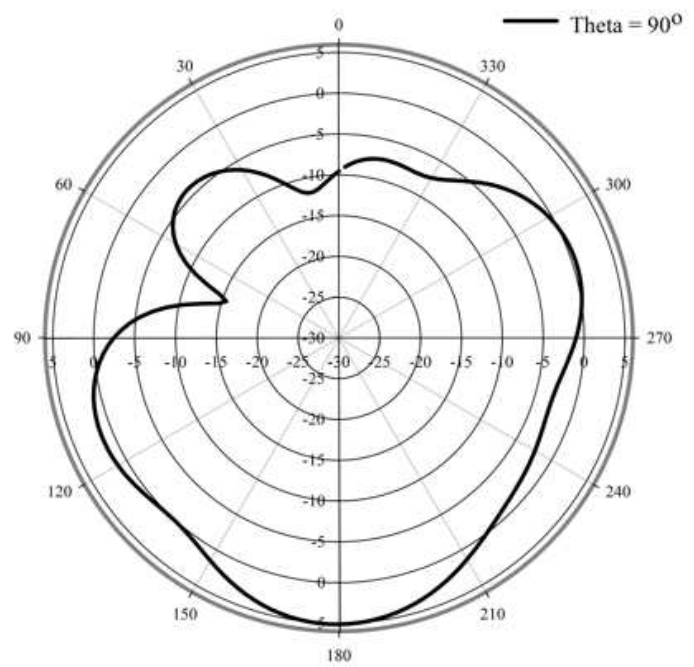

(a)

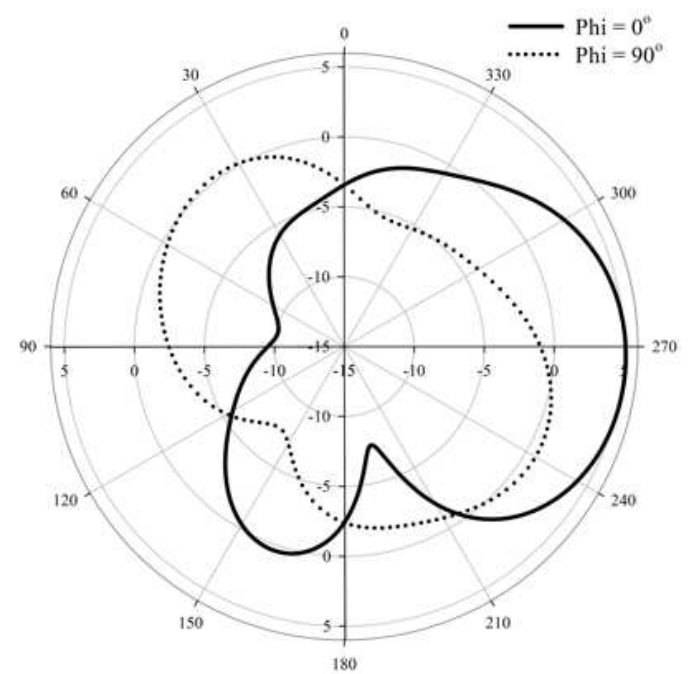

(c)

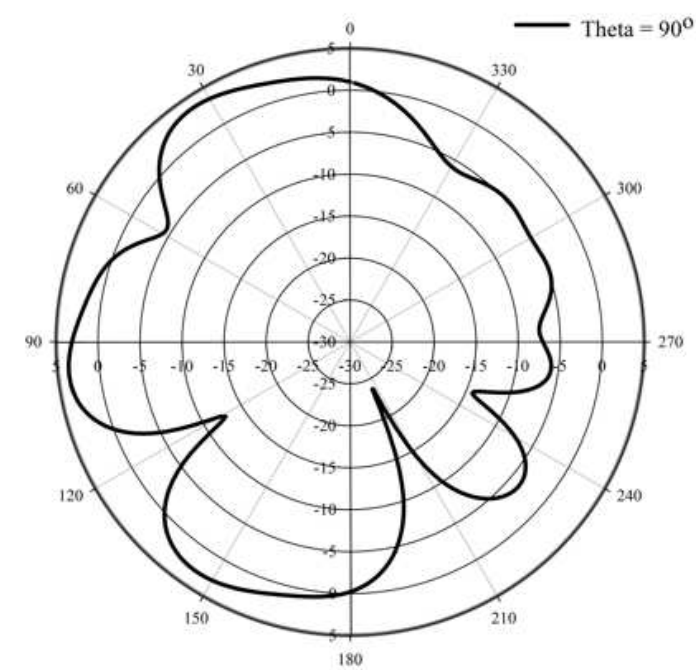

(b)

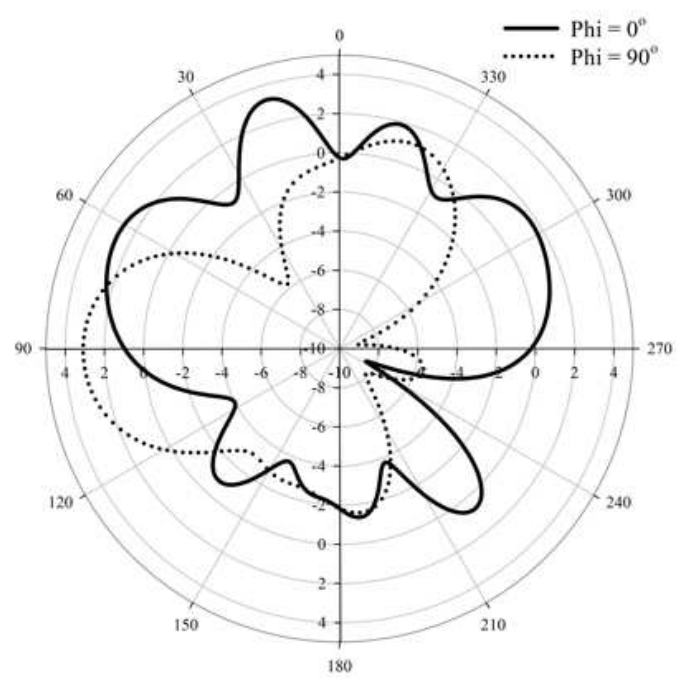

(d)

\section{Figure 9}

Simulated radiation patterns of the proposed MA for (a) theta $=90^{\circ}$ ( $x-y$ plane) at $4.8 \mathrm{GHz}$, (b) theta $=90^{\circ}$ ( $\mathrm{x}$-y plane) at $8.6 \mathrm{GHz},(\mathrm{c}) \mathrm{phi}=0^{\circ}(\mathrm{x}-\mathrm{z}$ plane $)$ and phi $=90^{\circ}(\mathrm{x}-\mathrm{y}$ plane $)$ at $4.8 \mathrm{GHz}$ and $(\mathrm{d})$ phi $=0^{\circ}(\mathrm{x}-\mathrm{z}$ plane $)$ and phi $=90^{\circ}(x-y$ plane $)$ at $4.8 \mathrm{GHz}$. 